\section{A7.17 MICROARRAY GENE EXPRESSION PROFILING OF RHEUMATOID ARTHRITIS PATIENTS FOR PREDICTION OF RESPONSE TO METHOTREXATE TREATMENT}

doi:10.1136/annrheumdis-2013-203221.17

K Mans, N Tandon, C Sohnrey, S Bolle, A Grützkau, GR Burmester, T Häupl, B Stuhlmüller. Department of Rheumatology and Clinical Immunology, DRFZ; Charité University Medicine Berlin, Charitéplatz 1, 10117 Berlin, Germany

Background and Objectives An early prediction of the outcome of particular DMARD therapies is necessary to treat the patients individually. This study aimed at defining predictive mRNA biomarkers in rheumatoid arthritis (RA) patients for the response to future treatment with methotrexate (MTX).

Materials and Methods For this purpose whole blood samples from 52 active RA patients before treatment were collected in PAXgene ${ }^{\circledR}$ Blood RNA Tubes (PreAnalytiX). Extraction of intracellular RNA including miRNA was performed according to PAXgene ${ }^{\circledR}$ Blood miRNA. Kit protocol. Extracted RNA samples were amplified employing the GeneChip ${ }^{\circledR}$ 3'IVT Express Kit and hybridised onto Affymetrix GeneChip ${ }^{\circledR} 133$ Plus 2.0 Arrays. Labelling was carried out with the GeneChip ${ }^{\circledR}$ Hybridisation, Wash and Stain Kit in a GeneChip ${ }^{\circledR}$ Fluidics Station 450. Generated signal data was normalised and evaluated using the Affymetrix Expression Console (MAS5.0) and the BioRetis online database for candidate gene selection (BioRetis $\mathrm{GmbH}$, Berlin). Classification of RA patients into good, moderate and non-responders was performed based on the DAS28 and EULAR response criteria after 3 months of MTX treatment. Prior to further expression analysis all patients were divided into two genetically more homogeneous subsets - one group of 29 donors expressing a specific HLA allele mRNA and one group of 23 not expressing this specific HLA mRNA. Hierarchical clustering of discriminating candidate genes was performed using the Genesis software v1.7.6 (IGB-TU, Graz) including and excluding 9 medium responders in the HLA positive cluster and 4 medium responders in the HLA negative cluster.

Results Gene comparison analysis was improved by separation of the patient collective into positive $(n=29)$ or negative $(n=23)$ groups expressing a specific HLA mRNA. Differential mRNA expression before treatment was determined between 14 good responders and 6 non-responders in the HLA positive and between 12 good responders and 7 non-responders in the HLA negative group, calculating expression change calls and fold changes. A clear discrimination between responders and non-responders to future MTX treatment was achieved with 16 distinct candidate genes for each group. These mRNA candidates will be validated in independent qPCR analyses and with further statistical cross validation algorithms.

Conclusions Early prediction of response to MTX monotherapy using microarray analyses is an opportunity for effective individual medication and therefore allows preventing side effects.

Employing specific response marker genes such as CD11c for anti-TNF monotherapy it is also of interest to define predictive biomarkers for the commonly used anti-TNF/MTX combination therapy not only preventing side-effects but also reducing costs.

\section{A7.18 PATHWAYS INDUCED BY ETANERCEPT AND ADALIMUMAB ARE SPECIFIC IN RA PATIENTS}

doi:10.1136/annrheumdis-2013-203221.18

1.*Romain Normand, ${ }^{1, *}$ Celine Derambure, ${ }^{1}$ Martine Hiron, ${ }^{1,2}$ Xavier Le Loët, ${ }^{1,2}$ Olivier Vittecoq, 1,2Thierry Lequerré. 'INSERM 905, Faculty of Medicine and Pharmacy, IRIB, Rouen, France; ${ }^{2}$ Rheumatology Department, Rouen University Hospital, France

*Equal contributors

Background The development of tumour necrosis factor alpha (TNF $\alpha$ ) inhibitors has led to major advances in the management of rheumatoid arthritis (RA). However, the molecular mechanisms of these agents are poorly understood.

Objective In order to better understand the specifics effects of Adalimumab and Etanercept, we identified and compared the gene expression profiling in peripheral blood mononuclear cells (PBMCs) from responder (R) RA patients treated by methotrexate (MTX)/ adalimumab (ADA) or MTX/etanercept (ETA) before and at 3 months after the beginning of the treatment.

Methods Nineteen RA patients were randomised to receive subcutaneously either ADA (40 mg each other week) or ETA (50 mg per week). Thirteen RA patients [average age: $48.6 \pm 14.3$ years old (yo), MTX: $13.1 \pm 6.3 \mathrm{mg} /$ week (w), initial DAS28: $5.5 \pm 0.6]$ received $\mathrm{ADA}$ while six RA patients (age: $52.5 \pm 16.1$ yo, MTX: $18.3 \pm 3 \mathrm{mg} / \mathrm{w}$, initial DAS28: $5.7 \pm 1.3$ ) were treated by ETA. The drug efficacy was evaluated with the DAS28 after 3 months of treatment according to the EULAR response criteria in order to discriminate $\mathrm{R}$ to $\mathrm{NR}$. A blood sample was carried out before the first injection and after 3 months in order to isolate PBMCs and extract total RNA for hybridisation on whole human genome Agilent $4 \times 44 \mathrm{k}$ array. A supervised analysis was performed using t-test (GeneSpring GX software) combined with a fold-change 1.5 in order to identify genes whose expression were altered in PBMCs after 3 months from $\mathrm{R}$ to each drug. Next, transcripts sets were analysed to identify potential functional pathways (Human Reactome). Gene expression profiles and functional pathways obtained for $\mathrm{R}$ to each anti-TNF $\alpha$ were compared.

Results Demographic, clinical and biological characteristics of all the patients were comparable before and after treatment administration. From the $\mathrm{R}(7 / 13)$ patients treated with $\mathrm{ADA}$, a combination of 63 transcripts involved in mTORC1-mediated Signalling was identified. Concerning the R $(2 / 6)$ treated by ETA, a combination of 16 transcripts involved in TNF Signalling, Death Receptor Signalling was observed. Any overlap was found when we compared these transcripts sets. Moreover, any common biological functions and functional pathways were found between R ADA and R ETA.

Conclusions The absence of overlap of transcripts sets and the absence of common pathways leading us to consider that molecular mechanisms of $\mathrm{ADA}$ and ETA are specific.

\section{A7.19 POSITIVE ASSOCIATION OF TAGAP RS212389 POLYMORPHISM WITH RHEUMATOID ARTHRITIS SUSCEPTIBILITY}

doi:10.1136/annrheumdis-2013-203221.19

A Chatzikyriakidou, PV Voulgari, AA Drosos. Rheumatology Clinic, Department of Internal Medicine, Medical School, University of Ioannina, Greece

Background and Objectives T-cell activation RhoGTPase activating protein (TAGAP) has recently been reported among genetic factors implicated in rheumatoid arthritis (RA) susceptibility. Up today, three polymorphisms at $6 \mathrm{q} 25$ locus, where TAGAP gene is mapped, have been associated with RA liability in patients of European descent: Rs394581, Rs212389, and Rs182429. According to a recent study, in which a comprehensive imputation of CEU HapMap single-nucleotide polymorphisms was conducted in a genome-wide association study, the polymorphism Rs212389 is the best predictor of TAGAP locus in RA predisposition at least in patients of European descent. In the present study, this polymorphism was genotyped, for first time, in RA samples as to validate the suggested association, while the genotypic analysis was extended to polymorphisms Rs394581 and Rs182429 in order to refine again the causative RA risk variant.

Materials and Methods One hundred thirty five patients and 147 controls subjects were enrolled in the study. Polymerase chain 